\title{
Spatiotemporal Manipulation of the Mismatch Repair System of Pseudomonas putida Accelerates Phenotype Emergence
}

\section{Fernández-Cabezón, Lorena; Cros, Antonin; Nikel, Pablo I.}

Published in:

ACS Synthetic Biology

Link to article, DOI:

10.1021/acssynbio.1c00031

Publication date:

2021

Document Version

Publisher's PDF, also known as Version of record

Link back to DTU Orbit

Citation (APA):

Fernández-Cabezón, L., Cros, A., \& Nikel, P. I. (2021). Spatiotemporal Manipulation of the Mismatch Repair System of Pseudomonas putida Accelerates Phenotype Emergence. ACS Synthetic Biology, 10(5), 1214-1226. https://doi.org/10.1021/acssynbio.1c00031

\section{General rights}

Copyright and moral rights for the publications made accessible in the public portal are retained by the authors and/or other copyright owners and it is a condition of accessing publications that users recognise and abide by the legal requirements associated with these rights.

- Users may download and print one copy of any publication from the public portal for the purpose of private study or research.

- You may not further distribute the material or use it for any profit-making activity or commercial gain

- You may freely distribute the URL identifying the publication in the public portal 


\title{
Spatiotemporal Manipulation of the Mismatch Repair System of Pseudomonas putida Accelerates Phenotype Emergence
}

\author{
Lorena Fernández-Cabezón, Antonin Cros, and Pablo I. Nikel*
}

Cite This: ACS Synth. Biol. 2021, 10, 1214-1226

Read Online

ABSTRACT: The development of complex phenotypes in industrially relevant bacteria is a major goal of metabolic engineering, which encompasses the implementation of both rational and random approaches. In the latter case, several tools have been developed toward increasing mutation frequencies, yet the precise control of mutagenesis processes in cell factories continues to represent a significant technical challenge. Pseudomonas species are endowed with one of the most efficient DNA mismatch repair (MMR) systems found in the bacterial domain. Here, we investigated if the endogenous MMR system could be manipulated as a general strategy to artificially alter mutation rates in Pseudomonas species. To bestow a conditional mutator

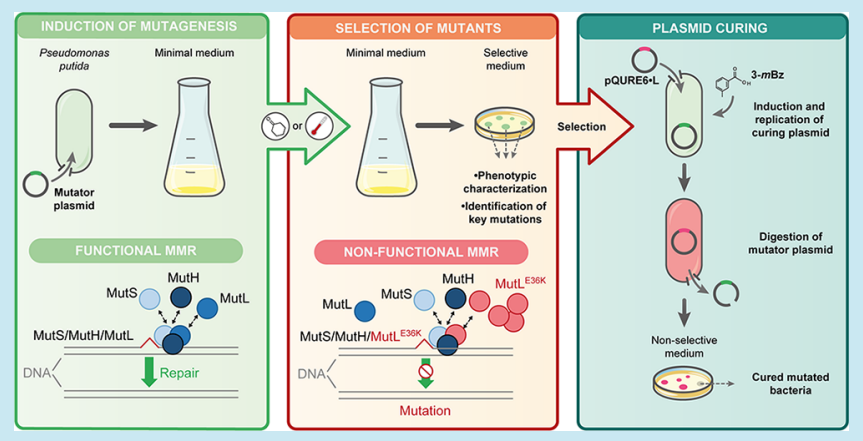
phenotype in the platform bacterium Pseudomonas putida, we constructed inducible mutator devices to modulate the expression of the dominant-negative $m u t L^{E 36 K}$ allele. Regulatable overexpression of $m u t L^{E 36 K}$ in a broad-host-range, easy-to-cure plasmid format resulted in a transitory inhibition of the MMR machinery, leading to a significant increase (up to 438-fold) in DNA mutation frequencies and a heritable fixation of mutations in the genome. Following such an accelerated mutagenesis-followed by selection approach, three phenotypes were successfully evolved: resistance to antibiotics streptomycin and rifampicin (either individually or combined) and reversion of a synthetic uracil auxotrophy. Thus, these mutator devices could be applied to accelerate the evolution of metabolic pathways in long-term evolutionary experiments, alternating cycles of (inducible) mutagenesis coupled to selection schemes toward the desired phenotype(s).

KEYWORDS: Pseudomonas putida, mismatch repair system, mutagenesis, synthetic biology, metabolic engineering, evolution

\section{INTRODUCTION}

Systems metabolic engineering and synthetic biology are used to guide the development of microbial cell factories (MCFs) capable of converting renewable raw materials into value-added compounds. $^{1-3}$ However, low productivities and product yields by most MCFs, even after comprehensive optimization of biosynthetic pathways, continue to make the implementation of economically viable bioprocesses difficult, especially at an industrial scale. ${ }^{4}$ Low product yields are often caused by a decrease in cell viability and genetic instability of MCFs under industrially relevant production conditions. ${ }^{5,6}$ For instance, the presence of growth inhibitors in renewable raw materials (e.g., crude glycerol and biomass hydrolysates) and the accumulation of toxic compounds during fermentation (including metabolic intermediates and target products) are known to negatively impact cell survival. ${ }^{7-9}$

Adaptive laboratory evolution (ALE), also known as evolutionary engineering, is a valuable tool to improve complex phenotypic traits that can be coupled with microbial growth (e.g., tolerance to inhibitors, substrate utilization, and growth temperature). ${ }^{10-12}$ At its core, ALE involves the extended propagation of a microbial strain or population, typically over hundreds of generations, in the presence of a desired selective pressure. Mutants that accumulate beneficial mutations will occasionally emerge and expand within the population over time. Selected mutants displaying enhanced phenotypes can be subsequently characterized and sequenced toward reverse engineering. ${ }^{10-15}$ Unlike purely rational approaches, ALE facilitates the identification of nonintuitive beneficial mutations that occur in a variety of genes in parallel without requiring any knowledge of the underlying genetic mechanisms.

Since intrinsic DNA mutation rates are typically very low (ranging in the order of $10^{-9}-10^{-10}$ per base pair per generation), ${ }^{16,17}$ small and transient increases in mutation frequency can significantly improve the accumulation of beneficial mutations in microbial populations. ${ }^{12,18}$ This rationale has been applied to certain ALE experiments,

Received: January 22, 2021

Published: April 12, 2021 
where the genetic diversity of a microbial population was increased before and/or during growth under restrictive culture conditions. ${ }^{5,15,19,20}$ Chemical and/or physical mutagenesis techniques have been traditionally used due to their simplicity and wide applicability, ${ }^{21,22}$ but other genome-wide random mutagenesis techniques can also be applied for this purpose. $^{5}$ Mutator strains, i.e., bacteria displaying higher mutation rates, frequently have mutations in one or several genes encoding DNA repair or error-avoidance systems. ${ }^{23}$ Most bacteria control DNA substitution rates through overlapping DNA repair mechanisms, subdivided into three main categories: (i) base selection, (ii) proofreading, and (iii) mismatch repair (MMR). ${ }^{24}$ Base selection encompasses the discrimination between correct and incorrect nucleotides by DNA polymerase, while proofreading is the subsequent editing of the newly incorporated nucleotide by a $3^{\prime} \rightarrow 5^{\prime}$ exonuclease activity that hydrolyzes incorrect bases. Following replication, newly replicated DNA is checked by a MMR system that recognizes and corrects mismatches resulting from replication errors. ${ }^{24}$ Specific mutations in components of MMR (e.g., mutL and $m u t S)$ or in proofreading DNA polymerases (e.g., dnaQ), as well as the overexpression of certain dominant-negative mutator alleles of the same genes, are known to result in mutator phenotypes. ${ }^{23,25}$ Conditional mutator phenotypes have been applied to the phenotypic optimization of MCFs. ${ }^{26-32}$ However, a major problem of these conditional phenotypes is the relatively low control of temporal activity afforded by the cognate devices. A typical drawback of these systems is that the ability to effectively halt DNA mutagenesis is limited, and the cells will continue to mutate even after a desired phenotype is achieved. ${ }^{33}$

Pseudomonas putida is a ubiquitous Gram-negative bacterium used for biotechnological and bioremediation applications. $^{34-37}$ Strain KT2440, for instance, is a well-established microbial chassis for handling the synthesis of difficult-toproduce chemicals involving harsh reactions and complex biochemistries. $^{36-40}$ Alas, metabolic engineering of P. putida still relies largely on trial-and-error approaches. While advanced genome-wide engineering tools are being constantly developed and optimized, ${ }^{41-44}$ complex phenotypes are the result of multilevel regulatory layers that are often difficult to design from first principles. ALE has recently started to be exploited in P. putida-based MCFs. ${ }^{45-50}$ On this background, we set out to explore if genome-wide mutation rates in P. putida (both wild-type strain and reduced-genome derivatives thereof) could be increased by the synthetic control of the MMR in this bacterium. ${ }^{51}$ To this end, we have designed a toolbox to conditionally increase DNA mutation rates by specifically interfering with the endogenous MMR system, thereby accelerating the evolution of specific phenotypes. Moreover, we focused on the adoption of emerging strategies to easily cure plasmid-borne mutator devices from bacterial populations, such that the temporal window of increased mutagenesis rates could be externally controlled. The application of this set of synthetic mutator devices has been systematically validated in evolution experiments targeting both antibiotic resistance and growth phenotypes via reversion of a synthetic auxotrophy.

\section{RESULTS AND DISCUSSION}

Construction of Broad-Host-Range, Plasmid-Based Mutator Devices to Increase DNA Mutation Rates. Pseudomonas species display one of the highest MMR efficiencies found in bacteria (e.g., as observed in P. fluorescens ${ }^{52}$ ). Therefore, we hypothesized that manipulating the endogenous MMR system could be a straightforward approach to increase DNA mutation rates in bacterial species of the Pseudomonas genus. In order to bestow a conditional mutator phenotype in the model bacterium $P$. putida, we constructed two inducible mutator devices, on the basis of wellcharacterized expression systems, to tightly modulate the expression of the mutator allele $m u t L^{E 36 K}$ from $P$. putida ${ }^{51}$ (Figures 1 and S1). The E36K amino acid change in MutL

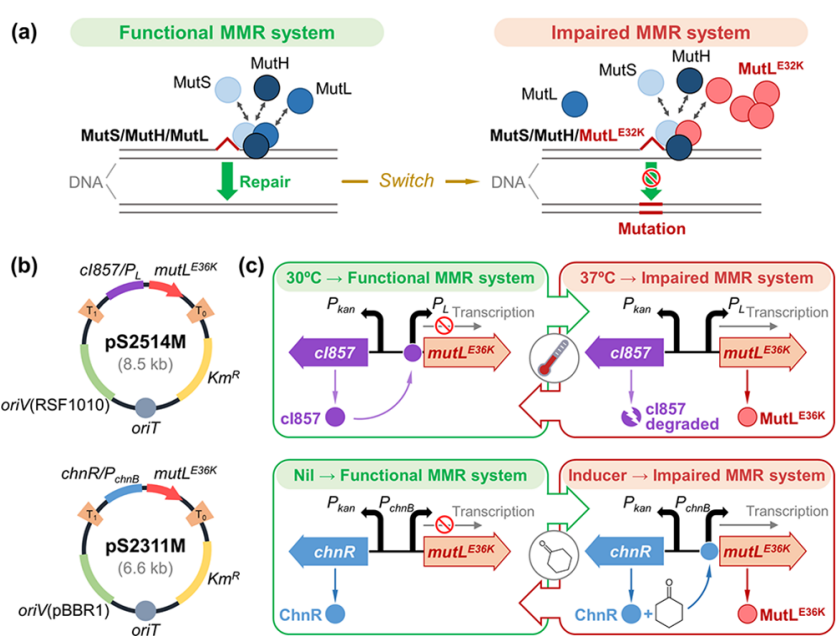

Figure 1. Broad-host-range mutator devices to conditionally increase mutation rates. (a) The bacterial DNA mismatch repair (MMR) system recognizes and fixes mutations that arise during DNA replication and recombination. MutS recognizes genomic DNA mismatches and recruits MutL. The MutL/MutS complex activates the MutH endonuclease, which cleaves the newly synthesized, unmethylated daughter strand at the nearest hemimethylated $\mathrm{d}$ (GATC) site and thereby marks it for a removal and repairsynthesis process that involves a variety of other proteins. Overexpression of the dominant-negative mutator allele $m u t L^{E 32 K}$ from E. coli increases mutation rates. ${ }^{25}$ (b) Structure of the two mutator devices used in this work. Plasmids pS2514M and pS2311M, on the basis of the Standard European Vector Architecture, ${ }^{99}$ were designed for thermoinducible or cyclohexanone-inducible expression of the mutator allele $m u t L^{E 36 K}$ from $P$. putida, respectively. Functional elements in the plasmids are not drawn to scale; $\mathrm{Km}^{R}$, kanamycinresistance marker. (c) Two strategies for tampering with the MMR system of $P$. putida. When using plasmid pS2514M, the temperaturesensitive repressor $c \mathrm{I} 857$ is constitutively produced at $28-32{ }^{\circ} \mathrm{C}$ and specifically binds to the $P_{L}$ promoter, mediating transcriptional repression of the gene cloned downstream (i.e., $\left.m u t L^{E 36 K}\right)$. When the temperature is set above $37{ }^{\circ} \mathrm{C}$ (e.g., $40{ }^{\circ} \mathrm{C}$ ), the expression of $m u t L^{E 36 K}$ can take place due to denaturation of $c \mathrm{I} 857$. When using plasmid pS2311M, the ChnR transcriptional regulator is constitutively synthesized and binds to the $P_{c h n B}$ promoter in the presence of its inducer (cyclohexanone), causing the expression of the gene cloned downstream (i.e., $m u t L^{E 36 K}$ ).

stems from a $106(\mathrm{G} \rightarrow \mathrm{A})$ point mutation in the corresponding allele (Figure S1). The overexpression of the homologous, dominant-negative allele $m u t L^{E 32 K}$ from Escherichia coli has been shown to result in a transitory inhibition of the MMR machinery, ${ }^{25,53}$ which leads to the heritable fixation of mutations in the genome by tampering with the MMR system (Figure 1a). The mutL $L^{E 36 \mathrm{~K}}$ allele, in contrast, has been exploited for genome engineering approaches specifically developed for P. putida and related species. ${ }^{54}$ In our mutator 
devices, the expression of $m u t L^{E 36 K}$ is driven by two tightly regulated expression systems, i.e., the thermoinducible cI857/ $\mathrm{P}_{\mathrm{L}}$ system from bacteriophage $\lambda$ and the cyclohexanoneinducible $\mathrm{ChnR} / \mathrm{P}_{\text {chnB }}$ system from Acinetobacter johnsonii. Both expression vectors have been previously employed for heterologous gene expression in Gram-negative bacteria such as E. coli or P. putida. ${ }^{55-59}$ Thus, the $m u t L^{E 36 K}$ gene was cloned into vectors pSEVA2514 (cI857/ $\mathrm{P}_{\mathrm{L}}$ ) and pSEVA2311 (ChnR/ $\mathrm{P}_{\text {chnB }}$ ) to yield the mutator plasmids $\mathrm{pS} 2514 \mathrm{M}$ and $\mathrm{pS} 2311 \mathrm{M}$, respectively (Figure $1 \mathrm{~b}$ ). The subsequent transfer of the mutator devices and plasmids developed herein to various bacterial hosts is facilitated by adopting the rules set in the Standard European Vector Architecture (SEVA) platform. ${ }^{60}$ Moreover, the implementation of these two expression systems enables the user to decide whether the induction of the devices can be done by a temperature shift (to $40{ }^{\circ} \mathrm{C}$ ) or the addition of chemicals to the culture medium (cyclohexanone). These two approaches were selected as the first one $\left(c \mathrm{I} 857 / \mathrm{P}_{\mathrm{L}}\right)$ relies on relieving the transcriptional repression mediated by the cI857 protein when it gets degraded at $40{ }^{\circ} \mathrm{C}$, whereas the $\mathrm{ChnR} / \mathrm{P}_{c h n B}$ system acts via direct activation of the transcriptional response upon addition of a low-cost, small-molecule inducer (Figure 1c). The thermal induction of plasmids pSEVA2514/M was done at $40{ }^{\circ} \mathrm{C}$ (instead of $42{ }^{\circ} \mathrm{C}$, reported as the most efficient temperature for inactivation of the $c \mathrm{I} 857$ repressor $^{61}$ ), because $P$. putida KT2440 only survives short periods of exposure at $42{ }^{\circ} \mathrm{C}$, but it can grow for several hours at $40{ }^{\circ} \mathrm{C}$ as indicated previously. ${ }^{57}$ Moreover, thermal induction facilitates alternating cycles of noninduction and induction of DNA mutagenesis by temperature shifts, without the need of removing the inducers from the culture medium (typically difficult and time-consuming). The next step was the calibration of these tools as indicated in the sections below.

Emergence of Antibiotic Resistance Phenotypes in $P$. putida Carrying Synthetic Mutator Devices. To investigate the functionality of the mutator devices, the occurrence of antibiotic-resistant mutants was assessed in bacterial cultures grown in liquid medium. Two types of antibiotic resistance were selected to this end, namely, rifampicin (Rif) and streptomycin (Str), and the systems were first tested in the wild-type strain KT2440. In these experiments, control strains (i.e., P. putida KT2440/ pSEVA2514 and KT2440/pSEVA2311) and their derivatives carrying the conditional mutator devices (i.e., P. putida $\mathrm{KT} 2440 / \mathrm{pS} 2514 \mathrm{M}$ and $\mathrm{KT} 2440 / \mathrm{pS} 2311 \mathrm{M}$ ) were cultured at $30{ }^{\circ} \mathrm{C}$ in nonselective $\mathrm{M} 9$ minimal medium containing $20 \mathrm{mM}$ glucose and subjected to the mutagenesis protocol indicated in Figure 2 and the Methods. In the case of strains carrying vectors with the $c \mathrm{I} 857 / \mathrm{P}_{\mathrm{L}}$ expression system, cultures were shifted at $40{ }^{\circ} \mathrm{C}$ for $15 \mathrm{~min}$ for induction, whereas liquid cyclohexanone was added at $1 \mathrm{mM}$ (and not removed afterward) in cultures of the strains transformed with vectors bearing the $\mathrm{ChnR} / \mathrm{P}_{\text {chnB }}$ system. Cultures were reincubated at $30{ }^{\circ} \mathrm{C}$ and halted at different phases of bacterial growth (i.e., early exponential, midexponential, or stationary phase) to assess the appearance of target phenotypes.

The occurrence of mutants developing resistance to either Rif or Str was investigated in bacterial populations after the treatments indicated above. Resistance to these antibiotics has been widely used for the investigation of spontaneous and induced mutagenesis processes in Gram-negative bacteria. ${ }^{62-64}$ Rifampicin-resistant $\left(\mathrm{Rif}^{\mathrm{R}}\right)$ and streptomycin-resistant $\left(\mathrm{Str}^{\mathrm{R}}\right)$ phenotypes occur due to the appearance of mutations in the

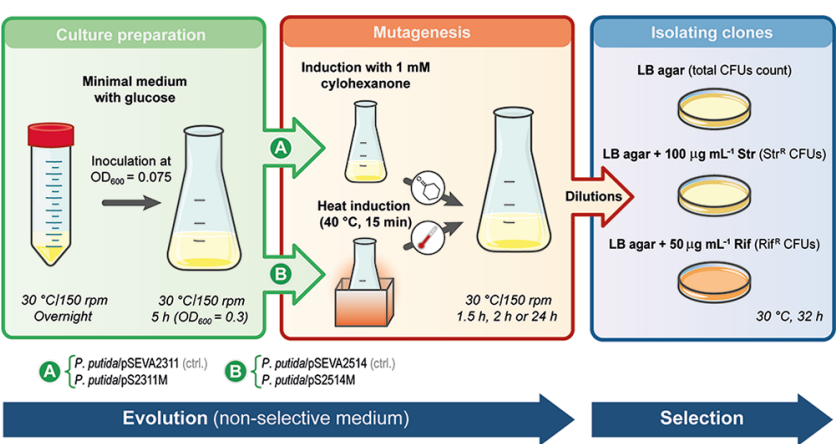

Figure 2. Experimental setup for the evolution of $P$. putida strains carrying mutator plasmids. Control (ctrl.) strains (i.e., P. putida KT2440/pSEVA2311 and KT2440/pSEVA2514, bearing empty vectors) and conditional-mutator strains (i.e., P. putida KT2440/ pS2311M and KT2440/pS2514M) were incubated in shaken-flask cultures in a nonselective medium (i.e., M9 minimal medium containing $20 \mathrm{mM}$ glucose). After $5 \mathrm{~h}$, when the cultures reached an optical density at $600 \mathrm{~nm}\left(\mathrm{OD}_{600}\right)$ of 0.3 , the expression systems were induced either thermally (incubating the flasks in a water bath) or chemically (adding liquid cyclohexanone to the medium). The cultures were reincubated at $30{ }^{\circ} \mathrm{C}$ with shaking, and the process was stopped after $1.5 \mathrm{~h}$ (early exponential phase, $\mathrm{OD}_{600}=0.6$ ), $2 \mathrm{~h}$ (midexponential phase, $\mathrm{OD}_{600}=1$ ) or $24 \mathrm{~h}$ (stationary phase). In the case of cultures of $P$. putida KT2440 carrying either vector pSEVA2311 or plasmid pS2311M, the biomass was washed twice with phosphate buffer to remove any traces of cyclohexanone. Several aliquots were plated onto a selective solid medium [e.g., LB agar supplemented with streptomycin (Str) or rifampicin (Rif)] to assess the appearance of mutants in the bacterial population [e.g., rifampicinresistant $\left(\mathrm{Rif}^{\mathrm{R}}\right)$ or streptomycin-resistant $\left(\mathrm{Str}^{\mathrm{R}}\right)$ mutants]. The total number of viable cells in the bacterial cultures was estimated by plating dilutions of the cultures on nonselective solid medium (e.g., LB agar). CFU, colony-forming unit.

$r p o B$ and $r p s L$ genes, encoding the $\beta$-subunit of RNA polymerase and the $30 \mathrm{~S}$ ribosomal protein S12, respectively. ${ }^{62-65}$ Mutation frequencies were estimated by assessing the frequency of occurrence of $\mathrm{Rif}^{\mathrm{R}}$ or $\mathrm{Str}^{\mathrm{R}}$ cells on the total number of viable cells in the bacterial population for each tested experimental condition (Figure 3). In all accelerated mutagenesis experiments, we observed a significantly higher number of $\mathrm{Rif}^{\mathrm{R}}$ and $\operatorname{Str}^{\mathrm{R}}$ mutants isolated in selective conditions in bacterial clones carrying a mutator device compared to their respective control strains (Figure 3). A visual example of this general trend is presented in Figure S2. The number of $\mathrm{Rif}^{\mathrm{R}}$ and $\mathrm{Str}^{\mathrm{R}}$ colonies present in $5 \mathrm{~mL}$ of nondiluted cultures of $P$. putida KT2440/pSEVA2311 (plated after concentrating the biomass by centrifugation and resuspension) was roughly similar to that in selective plates seeded with only $100 \mu \mathrm{L}$ of an undiluted culture of $P$. putida $\mathrm{KT} 2440 / \mathrm{pS} 2311 \mathrm{M}$. When these differences were quantified, the frequency of appearance of $\mathrm{Rif}^{\mathrm{R}}$ and $\mathrm{Str}^{\mathrm{R}}$ mutants in P. putida KT2440/pS2311M was 438- and 10-fold higher, respectively, as compared to the control strain when the induction of the expression system was stopped in the early exponential growth phase (Figure 3a). In the same experimental conditions, the frequency of occurrence of Rif ${ }^{R}$ and $\operatorname{Str}^{\mathrm{R}}$ mutants in P. putida KT2440/pS2514M was 45 - and 14-fold higher compared to the control strain, respectively (Figure $3 \mathrm{~b}$ ). Similar relative mutation frequencies were observed when the cultures of the different recombinant strains were prolonged until reaching midexponential and stationary phase (Figure 3). The largest differences in mutation 


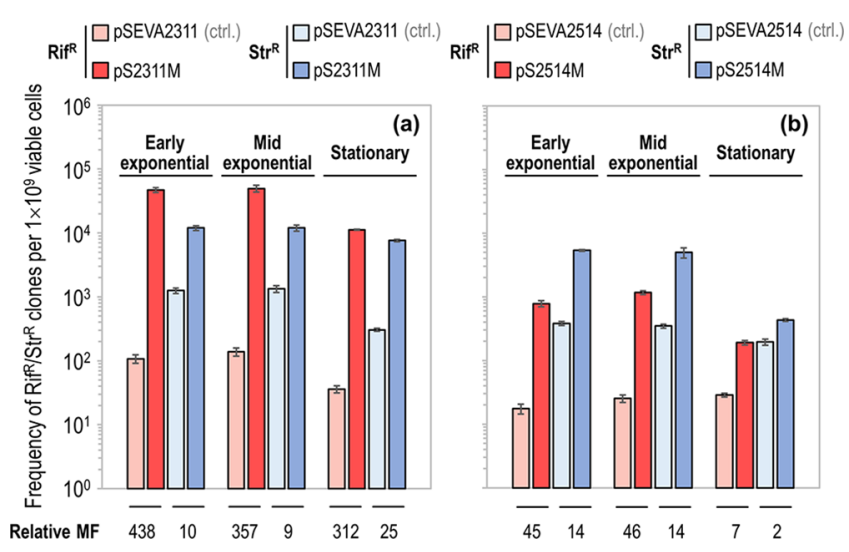

Figure 3. Evolution of antibiotic resistance in $P$. putida using conditional mutator devices. $P$. putida strains carrying the systems inducible by cyclohexanone (a) and temperature shifts (b) were evolved by following the mutagenesis protocol described in Figure 2. Culture aliquots were plated onto selective medium [i.e., LB agar supplemented with $100 \mu \mathrm{g} \mathrm{mL}^{-1}$ streptomycin (Str) or $50 \mu \mathrm{g} \mathrm{mL}^{-1}$ rifampicin (Rif)] to determine the appearance of Rif-resistant $\left(\mathrm{Rif}^{\mathrm{R}}\right)$ or Str-resistant $\left(\mathrm{Str}^{\mathrm{R}}\right)$ mutants. The total number of viable cells was estimated by plating dilutions of each of the cultures onto LB agar plates. Two technical replicates and several dilutions for the replicates were performed for each bacterial strain and per each selective condition. The columns represent the mean values of the mutation frequencies (MF, expressed as the number of mutant cells per $1 \times 10^{9}$ viable $P$. putida cells) from at least two independent experiments \pm standard deviation. Relative mutation frequencies were obtained by comparing the mutation frequency of the conditional mutator strain with the respective control (ctrl.) strain in the same experimental setup (i.e., expressed as fold-change).

frequencies were observed in actively growing cells (i.e., during the early or midexponential phase) as compared to bacteria harvested within the stationary phase. ${ }^{66-68}$ Differences detected in the basal level of the mutation frequencies between the two control strains (Figure 3) may be related to intrinsic structural properties of each plasmid (e.g., origins of replication or the level of expression of the regulatory genes therein) and the mutagenesis protocol used (either a temperature shift or the addition of a chemical inducer to the culture medium). Although the exact nature of these differences is difficult to quantify, these variables could exert some degree of stress in the host cells. ${ }^{69,70}$ The formation of reactive oxygen species, in turn, could lead to a slight increase in the mutation rates. ${ }^{71,72}$

Taken together, these experimental data attest the functionality of the mutator devices to temporarily increase the global mutation rate in P. putida. The differences detected in the mutation frequencies as elicited by the two devices may be related to the intrinsic properties of each of the plasmids that carry the mutator allele (e.g., origin of replication and promoter used, thereby affecting the transcriptional output) as well as to the protocols to induce the expression of $m u t L^{E 36 K}$. Moreover, differences in mutation frequencies arise depending on the method used for their estimation (i.e., counting the occurrence of $\mathrm{Rif}^{\mathrm{R}}$ or $\mathrm{Str}^{\mathrm{R}}$ clones). On the one hand, mutation frequencies and the actual spectrum of mutations vary at different chromosomal positions in several bacterial species, including $P$. putida. ${ }^{73-75}$ Other genetic factors, such as the orientation of the target gene in the replication fork, its level of transcription, and/or the immediately flanking nucleotides, can also influence the mutation frequency. ${ }^{73,74}$ On the other hand, the nature of the mutations acquired by $r p o B(P P$ 0447) and rpsL ( $P P$ 0449) could lead to altered levels of resistance to both Rif and Str, which makes it difficult to use these phenotypes for a direct, quantitative estimation of global mutation rates in different bacterial strains. Factors such as the time and temperature of incubation in the selective medium (i.e., agar plates supplemented with antibiotic) also affect the estimation of mutation frequencies (e.g., due to the appearance of colonies of uneven sizes). ${ }^{64}$ Therefore, the utilization of alternative phenotypes is highly recommended for the calibration and validation of our mutator tool. This issue was undertaken as explained in the next section.

Reversion of a Uracil Auxotrophy in P. putida Using Mutator Devices. To further calibrate the mutator vectors

\section{Table 1. Bacterial Strains and Plasmids Used in This Work}

\begin{tabular}{|c|c|c|}
\hline bacterial strain & relevant characteristics ${ }^{a}$ & reference \\
\hline \multicolumn{3}{|c|}{ Escherichia coli } \\
\hline DH5 $\alpha$ & 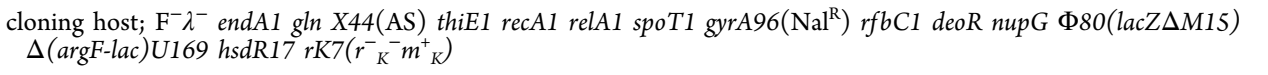 & $\begin{array}{l}\text { Meselson and } \\
\text { Yuan }\end{array}$ \\
\hline \multicolumn{3}{|c|}{ Pseudomonas putida } \\
\hline KT2440 & wild-type strain; derivative of $P$. putida mt-2 cured of the TOL plasmid pWW0 & Bagdasarian et al. ${ }^{97}$ \\
\hline EM42 & $\begin{array}{l}\text { derivative of } P \text {. putida KT2440; } \Delta \text { prophage1 } \Delta \text { prophage2 } \Delta \text { prophage3 } \Delta \text { prophage4 } \Delta T \mathrm{n} 7 \Delta e n d A-1 \Delta e n d A-2 \\
\quad \Delta h s d R M S \Delta \text { flagellum } \Delta T \mathrm{n} 4652\end{array}$ & $\underset{\text { al. }^{98}}{\text { Martínez-García et }}$ \\
\hline pyrF HM & Derivative of $P$. putida EM42; pyrF ${ }^{L y s 55 S T O P}(\mathrm{~A} 163 \mathrm{~T})$ & Aparicio et $a l^{76}$ \\
\hline \multicolumn{3}{|c|}{ Plasmids } \\
\hline pSEVA2311 & standard cyclohexanone-responsive expression vector; $\mathrm{Km}^{\mathrm{R}}$; oriV $(\mathrm{pBBR} 1), \operatorname{chnR} / P_{\operatorname{chnB}}$ & Benedetti et al. ${ }^{55}$ \\
\hline pSEVA2514 & standard thermo-inducible expression vector; $\mathrm{Km}^{\mathrm{R}}$; oriV(RSF1010), $c 1857 / P_{L}$ & Aparicio et $a l^{57}$ \\
\hline $\begin{array}{l}\text { pSEVA2514-rec2- } \\
\text { mutL }_{\text {E36K }}\end{array}$ & $\begin{array}{l}\text { derivative of vector pSEVA2514 carrying the rec2 recombinase and the dominant-negative mutator } m u t L^{E 36 K} \text { allele } \\
\text { from } P \text {. putida }\end{array}$ & Aparicio et al. ${ }^{51}$ \\
\hline pQURE6·L & conditionally replicating vector; derivative of vector $\mathrm{pJBSD} 1$ carrying XylS $/ \mathrm{P} m \rightarrow I-S c e I$ and $P_{14 g} \rightarrow m C h e r r y ; \mathrm{Gm}^{\mathrm{R}}$ & Volke et al. ${ }^{77}$ \\
\hline pS2311SG & derivative of vector pSEVA2311 with an engineered $I-S c e I$ recognition site for easy vector curing and $P_{E M 7} \rightarrow m s f G F P$ & this work \\
\hline pS2514SG & derivative of vector pSEVA2514 with an engineered $I-S c e I$ recognition site for easy vector curing and $P_{E M 7} \rightarrow m s f G F P$ & this work \\
\hline $\mathrm{pS} 2311 \mathrm{M}$ & derivative of vector pSEVA2311 carrying the dominant-negative mutator $m u t L^{E 36 \mathrm{~K}}$ allele from $P$. putida & this work \\
\hline pS2514M & derivative of vector pSEVA2514 carrying the dominant-negative mutator $m u t L^{E 36 K}$ allele from $P$. putida & this work \\
\hline pS2311SGM & derivative of vector pS2311SG carrying the dominant-negative mutator $m u t L^{E 36 \mathrm{~K}}$ allele from $P$. putida & this work \\
\hline pS2514SGM & derivative of vector pS2514SG carrying the dominant-negative mutator $m u t L^{E 36 \mathrm{~K}}$ allele from $P$. putida & this work \\
\hline
\end{tabular}

${ }^{a}$ Antibiotic markers: Km, kanamycin; Gm, gentamicin; Nal, nalidixic acid. 
and gain insight into evolved growth phenotypes beyond antibiotic resistance, we investigated the reversion of uracil auxotrophy of $P$. putida pyrF HM (Table 1). This strain is a derivative of the reduced-genome $P$. putida EM42 carrying a 163 $(\mathrm{A} \rightarrow \mathrm{T})$ mutation in pyrF, which results in a Lys55STOP change in the PyrF protein. ${ }^{76}$ This change, in turn, leads to the abortive translation of the cognate mRNA, and the strain thus lacks a functional orotidine 5 '-phosphate decarboxylase (i.e., $\mathrm{Ura}^{-}$phenotype), an essential activity for bacterial growth on minimal medium. In these experiments, the control strains, i.e., P. putida pyrF HM/pSEVA2514 and pyrF HM/pSEVA2311, and the conditional mutator strains, i.e., P. putida pyrF HM/ $\mathrm{pS} 2514 \mathrm{M}$ and $\mathrm{pyrF} \mathrm{HM} / \mathrm{pS} 2311 \mathrm{M}$, were cultured at $30{ }^{\circ} \mathrm{C}$ in nonselective medium (i.e., with uracil supplementation) and subjected to the mutagenesis protocol indicated in Figure 2. After treatment, the cultures were reincubated at $30{ }^{\circ} \mathrm{C}$ and harvested upon a doubling in the population size (i.e., early exponential phase). The emergence of uracil prototrophic mutants $\left(\mathrm{Ura}^{+}\right)$in the evolved bacterial populations was determined by seeding M9 minimal medium agar plates with glucose but without uracil supplementation. Mutation frequencies were estimated by assessing the frequency of occurrence of $\mathrm{Ura}^{+}$mutants on the total number of viable cells in the population for each tested experimental condition (Figure 4a). A significantly higher number of $\mathrm{Ura}^{+}$mutants were isolated from the bacterial populations carrying the conditional mutator devices as compared to their respective control strains, again validating the functionality of the mutator tools. In fact, we only isolated a negligible number (0-4) of spontaneous $\mathrm{Ura}^{+}$mutants in the bacterial populations of control strains under these experimental conditions. We estimated that mutation frequencies with either the cyclohexanone-inducible or thermoinducible mutator systems were within the same range (i.e., 750 and $860 \mathrm{Ura}^{+}$mutants per $1 \times$ $10^{9}$ viable $P$. putida cells, respectively, Figure 4a). The next objective in this experiment was studying the nature of the mutations acquired by the $\mathrm{Ura}^{+}$clones.

The Conditional Mutator Phenotype Favors the Emergence of Transition Mutations in the Genome. To investigate the nature of the mutations introduced with the mutator devices, the whole pyrF gene $\left(P P_{-} 1815\right)$ was amplified by high-fidelity PCR from several $\mathrm{Ura}^{+}$clones and the resulting amplicons were sequenced (Figure 4b). All the revertant (i.e., $\mathrm{Ura}^{+}$) clones had a very similar growth phenotype on M9 minimal medium with glucose as the only carbon source, when compared both to each other or their parental strain EM42 (Figure S3a,d). First, we analyzed and catalogued the mutations that may occur spontaneously at codon 55 of the pyrF gene (Figure S3e). Next, we isolated multiple $\mathrm{Ura}^{+}$mutants from two independent evolution experiments performed with the conditional mutator strains (i.e., P. putida pyrF HM/pS2514M and pyrF HM/pS2311M). The DNA transitions $164(\mathrm{~A} \rightarrow \mathrm{G})$ or $163(\mathrm{~T} \rightarrow \mathrm{C})$, which both eliminate the premature STOP codon in the $\operatorname{pyr}^{163(\mathrm{~A} \rightarrow \mathrm{T})}$ variant that leads to uracil auxotrophy, were equally frequent in mutants analyzed across different independent experiments (Figure $4 \mathrm{~b}, \mathrm{c}$ ). These observations indicate that the mutator devices seem to mediate transition mutations, i.e., changes from a purine nucleotide to another purine (i.e., $\mathrm{A}: \mathrm{T} \leftrightarrow \mathrm{G}$ :C) or a pyrimidine nucleotide to another pyrimidine ( $\mathrm{C}: \mathrm{G} \leftrightarrow \mathrm{T}: \mathrm{A})$. Note that only these two transitions lead to the disappearance of the premature STOP codon and to the production of a potentially functional PyrF protein (Figure S3e). When the

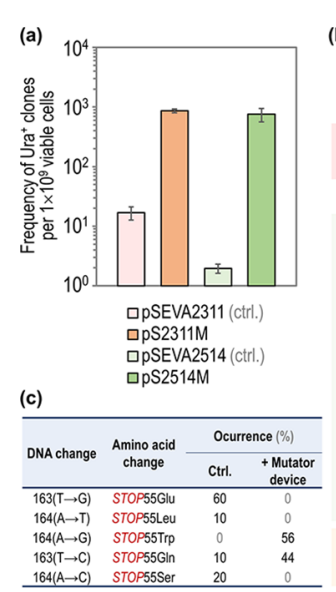

(b)

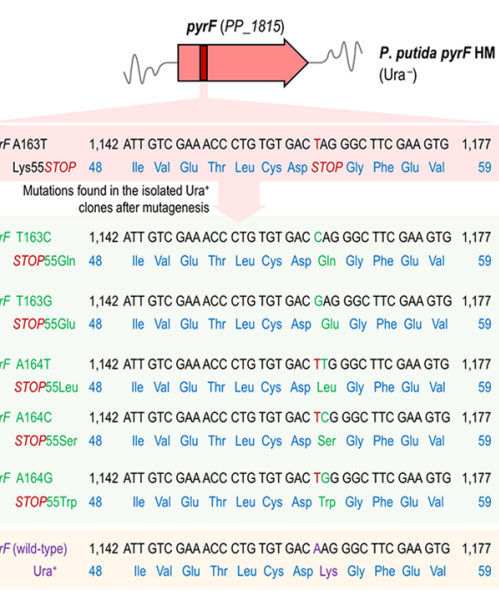

Figure 4. Reversion of a synthetic uracil auxotrophy in P. putida using mutator devices. (a) P. putida pyrF HM, carrying the pyrF ${ }^{\text {Lys55STOP }}$ allele that confers uracil auxotrophy ( $\mathrm{Ura}^{-}$phenotype), was transformed with the two conditional mutator systems (i.e., inducible by cyclohexanone or temperature shifts) or the corresponding control (ctrl.) vectors and evolved by following the mutagenesis protocol described in Figure 2. Several aliquots of these bacterial cultures were plated on selective solid medium (i.e., M9 minimal medium containing glucose as the only carbon source) to estimate the appearance of uracil prototrophic mutants $\left(\mathrm{Ura}^{+}\right)$in the population. The total number of viable cells was estimated by plating dilutions of the same cultures onto M9 minimal medium plates supplemented with $20 \mathrm{mM}$ glucose and $20 \mu \mathrm{g} \mathrm{mL}^{-1}$ uracil. Two technical replicates and several dilutions for the replicates were performed for each bacterial strain and per each selective culture condition. The columns represent the mean values of the mutation frequencies (expressed as the number of mutant cells per $1 \times 10^{9}$ viable $P$. putida pyrF HM cells) from at least two independent experiments \pm standard deviation. (b) Mutations found in the pyrF gene ( $P P_{-}$1815) in the $\mathrm{Ura}^{+}$mutants isolated from two independent experiments. A total of eight $\mathrm{Ura}^{+}$mutants for each mutator/control strain were analyzed. (c) Frequency of mutation occurrence in a control (ctrl.) strain and in the strain carrying the conditional mutator devices. Stop codons are indicated with the abbreviation STOP.

pyrF sequence was analyzed in the few $\mathrm{Ura}^{+}$mutants isolated from the experiments with the controls strains, we found a significant enrichment of transversion mutations, e.g., 163( $\mathrm{T} \rightarrow$ $\mathrm{G}), 164(\mathrm{~A} \rightarrow \mathrm{T})$, and $164(\mathrm{~A} \rightarrow \mathrm{C}$ ) (Figure $4 \mathrm{c}$ ). Interestingly, we could not isolate $\mathrm{Ura}^{+}$mutants displaying the wild-type pyrF sequence (i.e., with a Lys residue at position 55 of PyrF; Figure $4 \mathrm{~b})$ in any of these experiments. This finding may be simply due to probabilistic reasons (i.e., number of clones isolated and analyzed or the topology of the gene and access to the MMR machinery).

In agreement with our results, Long et al. ${ }^{52}$ showed that transition mutations are 16- to 82-fold more abundant than transversions in bacterial strains lacking a functional MMR system (Deinococcus radiodurans and P. fluorescens), in sharp contrast to the mere $<3$-fold found in the wild-type strains (i.e., spontaneously occurring). Horst et $a l^{23}$ also indicated that DNA transitions and frameshift mutations were more abundant in E. coli cells lacking a functional MMR system. Regardless of the nature of the mutations introduced by these tools, these experiments show that the conditional mutator devices can be used to accelerate the emergence of different phenotypes. However, a major limitation of this set of plasmidborne devices is the difficulty of curing them from the target cells, even in the absence of selective pressure. This 
shortcoming was fixed by constructing a new generation of "curable" mutator devices as explained below.

Design and Validation of a New Generation of Plasmid-Based, Easy-to-Cure Mutator Devices for Gram-Negative Bacteria. Previous attempts to cure isolated clones from the set of mutator plasmids based on vectors pSEVA2311 and pSEVA2514 proved unsuccessful, even after $>10$ repeated passages of individual colonies under nonselective conditions (data not shown). This situation not only precludes precise temporal control of the accelerated evolution protocol but also prevents the precise assessment of the (potential) occurrence of secondary mutations in the genome that do not have a selectable phenotype associated. In particular, whole-genome sequencing needs to be performed to study the frequency and nature of mutations arising in conditional mutator strains as well as the global mutation rates, as opposed to the local effects in individual genes that confer a macroscopic phenotype. In order to overcome this state of affairs and due to the tedious work required to cure the mutator and control plasmids in all the strains previously tested, we decided to build a new version of the easy-to-cure mutator systems using a technology recently developed in our laboratory. This methodology relies on the target curing of vectors by means of in vivo digestion mediated by the I-SceI homing endonuclease. ${ }^{77}$ For this purpose, we constructed vectors pS2311SG, pS2514SG, pS2311SGM, and pS2514SGM by USER assembly (Tables 1 and S1). These standardized vectors, which are all derivatives of pSEVA2311, pSEVA2514, pS2311M, and pS2514M, respectively, contain (i) an engineered I-SceI recognition site that can be recognized and cleaved off by the endonuclease I-SceI of Saccharomyces cerevisiae $^{78}$ and (ii) a module for the constitutive expression of $m s f G F P$ (i.e., $P_{E M 7} \rightarrow m s f G F P$, where the gene encoding the monomeric superfolder GFP is placed under control of the synthetic $P_{E M 7}$ promoter) (Figure 5a). This last module facilitates the selection of bacterial clones by the examination of the green-fluorescent colonies under blue light during the plasmid curing protocol. To this end, the accelerated mutagenesis protocol was upgraded by including a plasmidcuring step (presented in Figure S4). In this case, isolated clones are transformed with a helper plasmid that carries the gene encoding the I-SceI endonuclease under the control of the 3-methylbenzoate (3- $\mathrm{mBz}$ )-inducible $\mathrm{XylS} / \mathrm{Pm}$ expression system. Loss of the plasmid carrying the mutator device can be easily inspected as the corresponding colonies will also lose green fluorescence. Importantly, the presence of mutator plasmids does not affect the growth profile of the host (Figure S5).

In these experiments, we first subjected the control strains (i.e., P. putida KT2440/pS2514SG and KT2440/pS2311SG) and the conditional mutator strains carrying the new set of plasmids (i.e., P. putida KT2440/pS2514SGM and KT2440/ pS2311SGM) to the standard mutagenesis protocol to confirm the functionality of the easy-to-cure devices (Figure S4). We investigated the emergence of $\operatorname{Str}^{\mathrm{R}}$ mutants after implementing the accelerated mutagenesis protocol, and new induction conditions were likewise tested. As expected, most of the recombinant strains harboring the easy-to-cure plasmids behaved quite similarly to the original strains carrying the first generation mutator devices (Table S2). The mutation frequency mediated by the mutator allele under control of the cI857/ $\mathrm{P}_{\mathrm{L}}$ expression system was essentially identical in all experiments, irrespective of whether the original or the
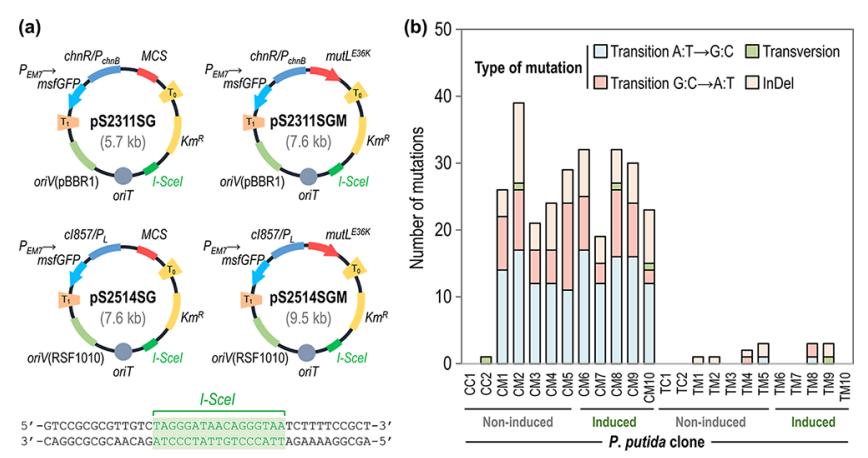

Figure 5. Design and implementation of a new generation of plasmidbased, easy-to-cure mutator devices for Gram-negative bacteria. (a) Plasmids pS2311SG, pS2514SG, pS2311SGM, and pS2514SGM, derivatives of vectors pSEVA2311, pSEVA2514, pS2311M, and pS2514M, respectively, were engineered with a I-SceI recognition site (indicated at the bottom of the figure) to render them compatible with the plasmid curing system based on targeted degradation mediated by the I-SceI endonuclease. ${ }^{77}$ These conditional mutator plasmids also carry a synthetic module for the constitutive expression of $m s f G F P$ (i.e., $P_{E M 7} \rightarrow m s f G F P$ ) that facilitates the selection of green-fluorescent clones by examining colonies under blue light. Functional elements in the plasmids not drawn to scale; $\mathrm{Km}^{R}$, kanamycin-resistance marker; MCS, standard multiple cloning site. (b) Mutation spectra caused by the mutator devices classified in functional categories. Control strains [i.e., P. putida KT2440/ pS2514SG (TC) and KT2440/pS2311SG (CC)] and the conditional mutator strains [i.e., P. putida KT2440/pS2514SGM (TM) and $\mathrm{KT} 2440 / \mathrm{pS} 2311$ SGM(CM)] were incubated in shaken flasks in a nonselective culture medium. After $5 \mathrm{~h}\left(\mathrm{OD}_{600}=0.3\right)$, the expression systems were induced thermally (in a water bath at $40^{\circ} \mathrm{C}$ for $15 \mathrm{~min}$ ) or chemically ( $1 \mathrm{mM}$ cyclohexanone). All cultures (induced and noninduced) were reincubated at $30{ }^{\circ} \mathrm{C}$ until reaching an $\mathrm{OD}_{600}$ of 0.6. Several dilutions of the cultures were plated on LB agar for the isolation of individual colonies. After curing off the mutator and control (i.e., empty) plasmids from the respective clones, genomic DNA was isolated and sequenced, and the readings were assembled. The emergence of transition $(A: T \rightarrow G: C ; G: C \rightarrow A: T)$, transversion $(A: T \rightarrow T: A ; \quad G: C \rightarrow T: A ; A: T \rightarrow C: G ; \quad G: C \rightarrow C: G)$, and small insertion-deletion ( $\mathrm{InDel})$ event $(<50 \mathrm{bp})$ mutations was analyzed in the individual strains. Clones $1-5$ and clones $6-10$ were obtained from induced and noninduced cultures, respectively.

upgraded set of plasmids was used. We detected a lower mutation frequency in strain KT2440/pS2311SGM (ca. 60\% lower than the values observed in strain KT2440/pS2311M under similar experimental conditions). Such a trait was consistently accompanied by a loss of green fluorescence in a significant proportion of the bacterial colonies isolated in solid medium, i.e., lysogeny broth (LB) agar, with or without Str supplementation. This result could be due to multiple factors, e.g., accumulation of loss-of-function mutations in the msfGFP gene stimulated by the same mutator device or unexpected decay or loss of the mutator plasmid in the absence of selection pressure [i.e., plasmid-borne kanamycin $(\mathrm{Km})$ resistance].

To investigate the hypothesis above, we repeated the accelerated mutagenesis protocol with strain KT2440/ pS2311SGM while maintaining $\mathrm{Km}$ selection on the plates. We observed that, in the presence of the selection pressure borne by the mutator plasmid, all bacterial colonies maintained green fluorescence and the overall mutagenesis frequencies were significantly higher than in all previous experiments (e.g., 270 -fold higher than in the experiments with the same plasmid but omitting Km; Table S2). Under these experimental 
conditions, the cyclohexanone-inducible mutator plasmids appear to exhibit leaky expression of the $m u t L^{E 36 K}$ allele, which led to similar mutagenesis frequencies in the absence or presence of the inducer (Table S2). This observation helps explaining why, in the absence of selection pressure, some cells may reduce the copy number of the pS2311SGM plasmid to alleviate mutagenic effects caused by (semi)constitutive expression of $m u t L^{E 36 \mathrm{~K}}$ or even force complete plasmid loss in some clones. Most of the colonies analyzed in these experiments showed a reduction in the plasmid copy number (as opposed to a total loss of plasmid) accompanied by a dramatic reduction in the fluorescence levels. At the bacterial population level, this phenomenon could further translate into an overall decrease of the global mutagenesis frequency. This behavior was not observed in strain KT2440/pS2514SGM, which appears to exhibit a lower, but more tightly regulated, expression level of the mutator allele than the $\mathrm{ChnR} / \mathrm{P}_{\operatorname{chnB}}$ counterpart (Table S2). Actually, extending the thermal induction of the $c 1857 / \mathrm{P}_{\mathrm{L}}$-based mutator devices from 15 to $30 \mathrm{~min}$ did not affect the global mutagenesis frequency. In either case, the genetic upgrading of the plasmid toolbox was meant to facilitate the easy curing of the mutator devices, and the results of these experiments are explained in the next section.

Easy-to-Cure Mutator Devices Enable a Tight Control of the Global Mutagenesis and Reveal a Wide Landscape of Genome Modifications upon Accelerated Evolution. The whole genome of several colonies isolated in nonselective medium (i.e., LB agar, 2-5 colonies for each experimental condition) was sequenced in order to assess the frequency and nature of mutations mediated by mutator devices. To this end, green-fluorescent colonies were selected after treatment (Figure S4) and transformed with the helper pQURE6.L plasmid, ${ }^{77}$ a conditionally replicating vector that requires the supplementation of $3-\mathrm{mBz}$ to the culture medium to ensure plasmid maintenance (Figure S6). As indicated above, plasmid pQURE6.L carries a synthetic module for the 3- $m$ Bz-inducible expression of the I-SceI endonuclease gene (i.e., XylS $/ \mathrm{Pm} \rightarrow \mathrm{I}$-SceI; Table 1 ) and a second module for the constitutive expression of $m R F P$ (i.e., $\mathrm{P}_{14 g} \rightarrow m$ Cherry), which together, facilitate quick curing of mutator plasmids by positive selection of red-fluorescent colonies (Figure S4; see also the Methods for details on the curing procedure). In all cases, the mutator devices could be easily cured upon introduction of plasmid pQURE6.L. Moreover, this helper plasmid could be typically cured during a simple overnight incubation of individual colonies in LB medium without $3-\mathrm{mBz}$ (data not shown), similar to the observations reported by Volke et al. ${ }^{77}$

Multiple colonies were isolated from the accelerated mutagenesis experiments using the upgraded mutator toolbox and, upon curing all plasmids, genomic DNA was extracted and purified prior to next generation sequencing. Whole-genome sequencing of genomic DNA enabled a precise elucidation of the nature of mutations elicited by these devices. In general, whole-genome sequencing data confirmed previous findings, as the emergence of transitions was a clear signature of clones carrying the $m u t L^{E 36 K}$ allele in different configurations (Figure $5 \mathrm{~b}$ and Table S3). These single-nucleotide polymorphisms were largely nonsynonymous, and transversions were extremely rare (i.e., 1 transversion per genome in a just a few isolated clones, no different from the frequency of transversions in any of the control strains). Importantly, the mutator devices also promoted the emergence of small insertion-deletion (InDel) mutations (mostly 1-2 bp; Figure $5 b$ and Table S4). Frameshift insertions were the most abundant type of InDel mutations detected in the isolated clones. Taken together and consistent with the results of the experiments reported in the previous section, the detailed exploration of mutations elicited by the cyclohexanoneinducible mutator devices indicates that this system promotes a nearly constitutive mutator phenotype. This feature, in turn, triggers a relatively high mutagenesis frequency over short induction periods, probably due to the leakiness of this system under these conditions.

Evolution of Dual Antibiotic Resistances in $P$. putida with Mutator Devices. The results in the previous sections indicate that the enrichment of point mutations afforded by the conditional mutator systems can be harnessed to select for monogenetic phenotype traits. Next, we asked if the system can be used to accelerate the emergence of more complex phenotypes. To this end, we adopted dual resistance to $\mathrm{Rif}^{\mathrm{R}}$ and $\operatorname{Str}^{\mathrm{R}}$ as a proxy. The upgraded mutagenesis protocol (Figure S4) was repeated by using P. putida KT2440 transformed with either vector pSEVA2311SG (control) or plasmid pS2311SGM (where the mutagenic mut $L^{E 36 K}$ allele is controlled by a $\mathrm{ChnR} / \mathrm{P}_{\operatorname{chn} B}$ module). After incubating the cultures in M9 minimal medium with $20 \mathrm{mM}$ glucose for $24 \mathrm{~h}$, the emergence of double-resistant mutants was estimated by plating the bacterial suspension onto LB agar supplemented with $\mathrm{Km}$, Rif, and Str. As observed in experiments involving single antibiotic resistances, a significant difference in the number of $\mathrm{Km}^{\mathrm{R}}$, $\mathrm{Rif}^{\mathrm{R}}$, and $\mathrm{Str}^{\mathrm{R}}$ was immediately evident even by the naked eye when comparing plates seeded with $P$. putida KT2440/pSEVA2311SG or $P$. putida KT2440/pS2311SGM (Figure 6a). Indeed, the emergence of double $\mathrm{Rif}^{\mathrm{R}}$ and $\mathrm{Str}^{\mathrm{R}}$ $P$. putida mutants was 6-folder higher in cultures of cells carrying the mutator device than in control experiments (Figure 6b). These results endorse the tools herein for evolving multigenic traits by the adoption of a simple protocol that can be iterated (and even automated) as needed.

\section{CONCLUSION}

In this work, we constructed two synthetic biology devices to control global mutation rates in P. putida (and, due to the nature of the vectors used, other Gram-negative bacteria as well) in a precise spatiotemporal fashion. The transient overexpression of the endogenous dominant negative $m u t L^{E 36 K}$ allele of $P$. putida interfered with the normal functioning of the endogenous MMR machinery, thereby increasing mutation frequencies in multiple strains of $P$. putida by 2 - to 438 -fold. Following a "mutagenesis followed by selection" approach, we successfully evolved three separate phenotypes arising from monogenic traits, i.e., resistance to the antibiotics Str and Rif and uracil prototrophy. Within this approach, we have first increased the genetic diversity in the bacterial population by inducing the activity of the synthetic mutator devices and, subsequently, isolated mutants onto a selective solid medium. In these experiments, the expression of the mutator $m u t L^{E 36 \mathrm{~K}}$ allele was driven from two inducible modules, i.e., the thermoregulated $c \mathrm{I} 857 / \mathrm{P}_{\mathrm{L}}$ and the cyclohexanone-regulated $\mathrm{ChnR} / \mathrm{P}_{\text {chnB }}$ expression systems, previously tailored for heterologous gene expression in Gram-negative bacterial species. We observed that the mutation frequencies achieved with the cyclohexanone-inducible mutator devices (i.e., vectors pS2311M and pS2311SGM, the first and second generation of the tools constructed in this study) were significantly higher 

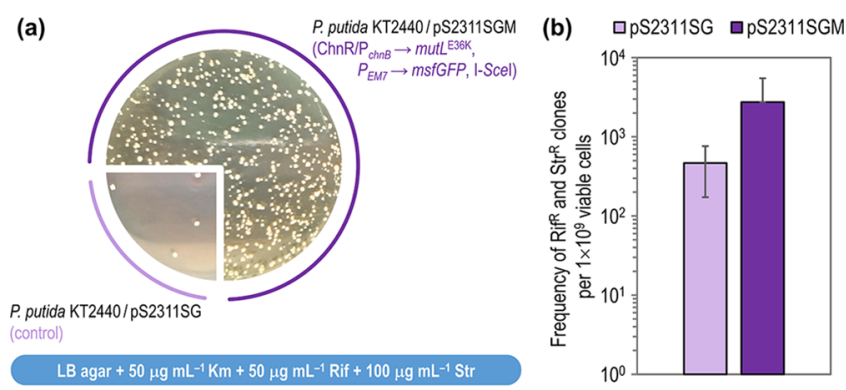

Figure 6. Evolution of a dual antibiotic resistance in $P$. putida using conditional mutator devices. The control strain P. putida KT2440/ pS2311SG and the conditional-mutator strain P. putida KT2440/ pS2311SGM were incubated in shaken-flask cultures in a nonselective medium (i.e., M9 minimal medium with $20 \mathrm{mM}$ glucose) for $24 \mathrm{~h}$ (stationary phase). Several aliquots of the cultures were plated onto a selective solid medium [i.e., LB agar with $50 \mu \mathrm{g} \mathrm{mL}^{-1}$ kanamycin (Km), $50 \mu \mathrm{g} \mathrm{mL}^{-1}$ rifampicin (Rif), and $100 \mu \mathrm{g} \mathrm{mL}^{-1}$ streptomycin (Str)] to assess the appearance of mutants [e.g., rifampicin-resistant $\left(\mathrm{Rif}^{\mathrm{R}}\right)$ and streptomycin-resistant $\left(\mathrm{Str}^{\mathrm{R}}\right)$ clones]. The total number of viable cells in the bacterial cultures was estimated by plating the dilutions of the cultures on nonselective solid medium (e.g., LB agar supplemented with $\mathrm{Km}$ ). Two replicates and several dilutions for the replicates were performed for each bacterial strain and per each selective culture condition. (a) Representative Petri dishes from these experiments were photographed for the sake of a rough comparison of the number of colonies observed for each culture under selective culture conditions. (b) Quantification of mutation frequencies. The columns represent mean values of the actual mutation frequencies (expressed as the number of mutant cells per $1 \times 10^{9}$ viable $P$. putida cells) from two independent experiments \pm standard deviation.

than those obtained with the thermoinducible mutators (i.e., vectors pS2514M and pS2514SGM) under most of the experimental conditions tested. In agreement with previous studies conducted with $E$. coli and related species, we also observed a higher emergence of transition and frameshift (InDel) mutations in cells displaying a temporarily tampered MMR system. ${ }^{23}$ We note, however, that this fact should not be interpreted as an inherent limitation of the mutator devices, since all of the available mutagenesis techniques exhibit mutation biases to different degrees. ${ }^{21,79}$ The preferential enrichment of a certain type of mutations is thus unavoidable, irrespective of the system used.

Interestingly, the cyclohexanone-triggered mutator devices had a significant level of leaky expression of $m u t L^{E 36 K}$, which in turn promoted a nearly constitutive mutator phenotype that led to high mutagenesis rates. The mutation frequencies achieved with this system were, however, lower than those reported with constitutive mutator strains where the mutator phenotype was originated by modifications in the components of the endogenous MMR system. For example, Kurusu et al. ${ }^{80}$ reported that the frequency of occurrence of $\mathrm{Rif}^{\mathrm{R}}$ mutants in a $\Delta$ mutS derivative of $P$. putida KT2440 was 1000 -fold higher than that in the wild-type strain. Since mutagenesis must be precisely controlled to avoid the extensive accumulation of deleterious mutations and to prevent genomic instability, the overexpression of mutator alleles should be driven from tightly regulated expression systems (which is always challenging, irrespective of the bacterial host ${ }^{59}$ ) or during short periods of time. Thus, the easy-to-cure mutator plasmids developed in this study, which can be rapidly removed from isolated clones displaying the phenotype of interest, offer a clear advantage over conventional mutator strains where the mutator phenotype is elicited by genomic (hence, essentially irreversible) modifications, as epitomized by the emergence of mutator phenotypes of $P$. aeruginosa in clinically relevant setups. ${ }^{81,82}$ In contrast with the results of the $\mathrm{ChnR} / \mathrm{P}_{\mathrm{chnB}}{ }^{-}$ dependent module, the thermoinducible mutator devices allowed for a tightly regulated expression of $m u t L^{E 36 K}$. This tool may be applied to long evolutionary experiments that involve alternating cycles of noninduction and induction of mutagenesis coupled to phenotype selection (e.g., growthcoupled approaches). When the induction conditions and the number of induction cycles are modified, a landscape of mutation rates could be achieved and adapted to the needs of each evolutionary experiment. The control of these parameters might be crucial for accelerating the evolution of complex phenotypes in industrial MCFs, since it has been previously shown that microbial adaptation to specific stresses is favored with certain mutation rates. ${ }^{83}$ Due to its particular metabolic architecture, this would likely be the case for P. putida as well. $^{84}$

Along the same line, the method herein suppresses the handling of chemical or physical mutagens (typically carcinogenic and, oftentimes, acutely toxic) for phenotype evolution. As an example, implementing physical methods for mutagenesis (e.g., UV irradiation) in liquid cultures is not only technically difficult but will also result in an uneven exposure of the cells to the irradiation source. ${ }^{85} \mathrm{UV}$ irradiation promotes a single type of mutation in the DNA (i.e., thymine dimer lesions), thereby reducing the mutational landscape that can be obtained with such methods. Thus, using mutator plasmids represents an advantage over the adoption of traditional mutagens, enabling safer operation conditions and circumventing the subsequent treatment of contaminated materials. Also, the thermoinducible mutator device described herein allows one to alternate the cycles of noninduction and induction of mutagenesis by merely controlling the incubation temperature, altogether suppressing the addition of any chemicals to the culture medium.

From a more general perspective, the MutL/MutS protein complex of the MMR machinery appears to be well-conserved in most bacterial species. ${ }^{86,87}$ For instance, the MutS protein from $P$. putida and the MutL protein from $P$. aeruginosa were shown to functionally complement $\Delta m u t S$ and $\Delta m u t L$ mutants of E. coli and Bacillus subtilis, respectively. ${ }^{80,88}$ Therefore, the broad-host-range mutator devices developed herein are expected to be functional in other bacterial hosts. In addition to their application for the accelerated evolution of phenotypes that depend on multiple mutations across the bacterial genome, the use of these devices also revealed an important feature of the MMR system relevant for synthetic biology. A number of genome modification approaches rely on specifically interfering with the bacterial MMR system to enable strand invasion. ${ }^{51,53,59,89}$ Besides the intended modifications (e.g., as encoded in mutagenic oligonucleotides), there are several secondary mutations that could occur due to the overexpression of mutagenic alleles. The tight spatiotemporal manipulation of this trait, afforded by the plasmids in this study, could enable a more precise control of the genome modifications by restricting the mutation landscape to the intended alterations.

\section{METHODS}

Bacterial Strains and Growth Conditions. The bacterial strains in this work are listed in Table 1. E. coli DH5 $\alpha$ was used 
for cloning and plasmid maintenance. E. coli and P. putida strains were routinely grown in lysogeny broth (LB) medium (10 $\mathrm{g} \mathrm{L}^{-1}$ tryptone, $5 \mathrm{~g} \mathrm{~L}^{-1}$ yeast extract, and $5 \mathrm{~g} \mathrm{~L}^{-1} \mathrm{NaCl}$ ) at 37 and $30^{\circ} \mathrm{C}$, respectively, in an orbital shaker at $150 \mathrm{rpm}$. For mutagenesis experiments, $P$. putida was grown in M9 minimal medium supplemented with $20 \mathrm{mM}$ glucose as the sole carbon source, as typically done when cultivating this species on sugars for physiological studies. ${ }^{84}$ Cyclohexanone was added at $1 \mathrm{mM}$ to cultures for the induction of $m u t L^{E 36 K}$ expression. When appropriate, antibiotics were also added at the following concentrations $\left(\mu \mathrm{g} \mathrm{mL}^{-1}\right)$ : gentamicin, $10 ; \mathrm{Km}, 50$; Str, 100; and Rif, 50. The supplementation of $20 \mu \mathrm{g} \mathrm{mL}^{-1}$ uracil was implemented to support bacterial growth of uracil-auxotrophic strains. Bacterial growth was estimated by measuring the optical density at $630 \mathrm{~nm}\left(\mathrm{OD}_{630}\right)$.

General DNA Manipulations and Sequencing. Molecular biology techniques were performed essentially as described in standard protocols. ${ }^{90}$ Oligonucleotides were purchased from Integrated DNA Technologies (IDT; Leuven, Belgium), and their sequences are provided in Table S1. DNA amplification was performed on a C1000 Touch Thermal Cycler (Bio-Rad Corp., Hercules, CA, USA) using Phusion $U$ Hot Start DNA Polymerase or Phusion Hot Start II DNA Polymerase from Thermo Fisher Scientific (Waltham, MA, USA). DNA fragments were purified with a NucleoSpin Gel and PCR Clean-up kit (Macherey-Nagel, Düren, Germany). Restriction enzymes and T4 DNA ligase were obtained from Thermo Fisher Scientific and were used according to the supplier's specifications. USER assembly was performed essentially as described by Nour-Eldin et al. ${ }^{91}$ with the commercial USER enzyme from New England BioLabs (NEB, Ipswich, MA, USA). Plasmid DNA was prepared with a NucleoSpin Plasmid EasyPure kit (Macherey-Nagel). E. coli chemical competent cells were prepared using the Mix \& Go E. coli Transformation Kit from Zymo Research (Irvine, CA, USA). DNA amplification from a single colony (i.e., colony PCR) was performed with One Taq $2 \times$ Master Mix (NEB). Electrocompetent $P$. putida cells were prepared by washing an overnight culture of $P$. putida with $300 \mathrm{mM}$ sucrose twice. ${ }^{92}$ All cloned inserts and DNA fragments were confirmed by DNA sequencing (Eurofins Genomics, Ebersberg, Germany).

Construction of Broad-Host-Range Mutator Expression Vectors. Plasmid pSEVA2514-rec2-mut $L_{E 36 \mathrm{~K}}{ }^{\mathrm{PP}}$, described by Aparicio et al., ${ }^{54}$ was double-digested with $\mathrm{XbaI}$ and HindIII to obtain a $1.9 \mathrm{~kb}$ DNA fragment corresponding to the dominant-negative mutator allele $m u t L^{E 36 \mathrm{~K}}$ of $P$. putida KT2440. The purified DNA fragment was subsequently ligated with the pSEVA2541 and pSEVA2311 vectors, previously digested with the same restriction enzymes, to generate plasmids pS2514M and pS2311M, respectively. The easy-tocure plasmids pS2514SG, pS2514SGM, pS2311SG, and pS2311SGM were subsequently constructed by USER assembly with the primers indicated in Table S1. These vectors contain an engineered I-SceI recognition site and an msfGFP gene under the control of the constitutive $\mathrm{P}_{E M 7}$ promoter (Figure S4) that make them compatible with the plasmid curation approach recently developed by Volke et al. ${ }^{77}$

Accelerated Evolution Experiments with $P$. putida Recombinant Strains Carrying Mutator Plasmids. Overnight precultures of the conditional mutator strains [e.g., P. putida KT2440/pS2514(SG)M and KT2440/pS2311(SG)$\mathrm{M}$ ] as well as of their respective control strains [e.g., P. putida $\mathrm{KT} 2440 / \mathrm{pS} 2514(\mathrm{SG})$ and $\mathrm{KT} 2440 / \mathrm{pS} 2311(\mathrm{SG})]$ were used to inoculate $25 \mathrm{~mL}$ of nonselective $\mathrm{M} 9$ minimal medium at an initial $\mathrm{OD}_{600}$ of 0.075 . After $5 \mathrm{~h}$ of incubation in an orbital shaker at $30{ }^{\circ} \mathrm{C}\left(\mathrm{OD}_{600}=0.3\right)$, the expression systems were induced thermally (by incubation at $40{ }^{\circ} \mathrm{C}$ for $15 \mathrm{~min}$ in a water bath) or chemically (by the addition of $1 \mathrm{mM}$ cyclohexanone). The cultures were subsequently reincubated at $30{ }^{\circ} \mathrm{C}$ with shaking and stopped after $1.5 \mathrm{~h}$ (early exponential phase, $\left.\mathrm{OD}_{600}=0.6\right), 2 \mathrm{~h}$ (midexponential phase, $\mathrm{OD}_{600}=1$ ), or $24 \mathrm{~h}$ (stationary phase, $\mathrm{OD}_{600}=3$ ). Several aliquots of the bacterial cultures were plated on selective solid medium (e.g., LB agar supplemented with $100 \mu \mathrm{g} \mathrm{mL}^{-1}$ Str or with $50 \mu \mathrm{g} \mathrm{mL} \mathrm{g}^{-1}$ Rif as appropriate) to determine the appearance of mutant cells (e.g., $\operatorname{Rif}^{\mathrm{R}}$ or $\mathrm{Str}^{\mathrm{R}}$ ) in the bacterial population. The total number of viable cells in the bacterial population was also estimated by plating the dilutions of the cultures on nonselective medium (e.g., LB agar plates). After 32 $\mathrm{h}$ of incubation at $30{ }^{\circ} \mathrm{C}$, the number of colony forming units (CFUs) in the different culture conditions was estimated by the visual inspection of the plates (see Figure S2 for an example). At least two biological replicates and two technical replicates were performed for each bacterial strain and selective culture condition, respectively.

Vector Curing Procedure for Easy-to-Cure Plasmids Carrying Mutator Devices. Overnight precultures of greenfluorescent colonies isolated from evolution experiments were transformed by electroporation with plasmid pQURE6.L (Table 1 and Figure S6). Transformed cells were recovered in LB medium supplemented with $2 \mathrm{mM} 3-\mathrm{mBz}$ for $2 \mathrm{~h}$. Dilutions were then plated on LB agar supplemented with 10 $\mu \mathrm{g} \mathrm{mL}^{-1} \mathrm{Gm}$ and $1 \mathrm{mM} 3-\mathrm{mBz}$. Red-fluorescent colonies that had lost the mutator plasmids were easily isolated after $24-48$ $\mathrm{h}$ of incubation at $30{ }^{\circ} \mathrm{C}$. For curing the helper pQURE6.L plasmid, overnight precultures of red-fluorescent colonies were grown and dilutions were plated on nonselective medium (e.g., LB agar). Nonfluorescent colonies were selected after $24 \mathrm{~h}$ of incubation and were stored for further analysis. The loss of both plasmids in the selected colonies was further confirmed by $\mathrm{Gm}$ and $\mathrm{Km}$ sensitivity (Figure S4).

Genomic DNA Purification, Library Construction, and Whole Genome Sequencing (WGS). DNA was purified using the PureLink Genomic DNA Purification kit (Invitrogen, Waltham, MA, USA) from $2 \mathrm{~mL}$ of overnight LB cultures inoculated from cryostocks prepared after curing the plasmids from the strains. The genomic DNA of each sample was randomly sheared into short fragments of about $350 \mathrm{bp}$ using ultrasonic interruption. Short and large DNA fragments were removed using magnetic bead size selection and subsequently verified by capillary gel electrophoresis. The obtained DNA fragments were subjected to library construction using the NEBNext DNA Library Prep kit (NEB), following the supplier's specifications. Library quality control was performed with a Qubit 2.0 fluorometer and an Agilent 2100 BioAnalyzer. Subsequent sequencing was performed using the Illumina NovaSeq 6000 PE150 platform. The original sequencing data acquired by high-throughput sequencing platforms recorded in image files were first transformed to sequence reads by base calling with the Illumina's CASAVA software. The sequences and corresponding sequencing quality information were stored in a FASTQ file. For quality control purposes, paired reads were discarded when: (i) either read contains adapter contamination, (ii) uncertain nucleotides (N) constitute $>10 \%$ of either read, or (iii) low quality nucleotides (base quality less than $5, Q \leq 5$ ) constitute $>50 \%$ of either read. The 
effective sequencing data were aligned with the reference sequence (NCBI Reference Sequence: NC_002947.4) through Burrows-Wheeler Aligner (BWA) software, ${ }^{93}$ and the mapping rate and coverage were counted according to the alignment results. The duplicates were removed by means of the SAMtools package. ${ }^{94}$ Single nucleotide polymorphisms (SNPs) and InDel mutations were detected using SAMtools and followed by annotation using ANNOVAR. ${ }^{95}$ Library construction, sequencing, and subsequent data quality control were performed by Novogene Co. Ltd. (Cambridge, United Kingdom).

\section{ASSOCIATED CONTENT}

\section{SI Supporting Information}

The Supporting Information is available free of charge at https://pubs.acs.org/doi/10.1021/acssynbio.1c00031.

Table S1: oligonucleotides used in this work; Table S2: mutation frequencies estimated with the different versions of mutator plasmids created in this work; Table S3: distribution of single nucleotide polymorphisms (SNPs) in evolved populations of P. putida; Table S4: distribution of small insertion-deletion (InDel) mutations in evolved populations of P. putida; Figure S1: protein sequence alignment of the $\mathrm{NH}_{2}$ terminal region of MutL proteins from different bacteria; Figure S2: appearance of rifampicin- and streptomycinresistant mutants in populations of $P$. putida KT2440 carrying a mutator device; Figure S3: growth profile and characteristics of selected $P$. putida $\mathrm{Ura}^{+}$mutants isolated in mutagenesis experiments; Figure S4: upgraded protocol for accelerated evolution of phenotypes using the new generation of easy-to-cure mutator devices; Figure S5: growth profile of engineered P. putida strains carrying mutator plasmids; Figure S6: physical map of the helper pQURE6 L plasmid (PDF)

\section{AUTHOR INFORMATION}

\section{Corresponding Author}

Pablo I. Nikel - The Novo Nordisk Foundation Center for Biosustainability, Technical University of Denmark, 2800

Kongens Lyngby, Denmark; 이이이.org/0000-0002-93137481; Phone: (+45 93) 5119 18; Email: pabnik@ biosustain.dtu.dk

\section{Authors}

Lorena Fernández-Cabezón - The Novo Nordisk Foundation Center for Biosustainability, Technical University of Denmark, 2800 Kongens Lyngby, Denmark

Antonin Cros - The Novo Nordisk Foundation Center for Biosustainability, Technical University of Denmark, 2800 Kongens Lyngby, Denmark

Complete contact information is available at: https://pubs.acs.org/10.1021/acssynbio.1c00031

\section{Author Contributions}

L.F.C. and P.I.N. designed the experimental plan and the overall research setup. L.F.C. and A.C. carried the experimental work and drafted the figures and the manuscript with further contributions by P.I.N. All authors discussed the results and interpreted the experimental data.

Notes

The authors declare no competing financial interest.

\section{ACKNOWLEDGMENTS}

We thank V. de Lorenzo and his team at CNB-CSIC (Madrid, Spain) for sharing research materials and for enlightening discussions. The financial support from The Novo Nordisk Foundation (grants NNF20CC0035580 and LiFe, NNF18OC0034818), the Danish Council for Independent Research (SWEET, DFF-Research Project 8021-00039B), and the European Union's Horizon 2020 Research and Innovation Programme under grant agreement No. 814418 (SinFonia) to P.I.N. is gratefully acknowledged. L.F.C. was supported by the European Union's Horizon 2020 Research and Innovation Programme under the Marie Skłodowska-Curie grant agreement No. 713683 (COFUNDfellowsDTU) and No. 839839 (DONNA).

\section{REFERENCES}

(1) Calero, P., and Nikel, P. I. (2019) Chasing bacterial chassis for metabolic engineering: A perspective review from classical to nontraditional microorganisms. Microb. Biotechnol. 12 (1), 98-124.

(2) Chen, Y., Banerjee, D., Mukhopadhyay, A., and Petzold, C. J. (2020) Systems and synthetic biology tools for advanced bioproduction hosts. Curr. Opin. Biotechnol. 64, 101-109.

(3) Choi, K. R., Jang, W. D., Yang, D., Cho, J. S., Park, D., and Lee, S. Y. (2019) Systems metabolic engineering strategies: Integrating systems and synthetic biology with metabolic engineering. Trends Biotechnol. 37 (8), 817-837.

(4) Ko, Y. S., Kim, J. W., Lee, J. A., Han, T., Kim, G. B., Park, J. E., and Lee, S. Y. (2020) Tools and strategies of systems metabolic engineering for the development of microbial cell factories for chemical production. Chem. Soc. Rev. 49 (14), 4615-4636.

(5) Fernández-Cabezón, L., Cros, A., and Nikel, P. I. (2019) Evolutionary approaches for engineering industrially-relevant phenotypes in bacterial cell factories. Biotechnol. J. 14 (9), 1800439.

(6) Gong, Z., Nielsen, J., and Zhou, Y. J. (2017) Engineering robustness of microbial cell factories. Biotechnol. J. 12 (10), 1700014.

(7) Amoah, J., Kahar, P., Ogino, C., and Kondo, A. (2019) Bioenergy and biorefinery: Feedstock, biotechnological conversion, and products. Biotechnol. J. 14 (6), No. 1800494.

(8) Poblete-Castro, I., Wittmann, C., and Nikel, P. I. (2020) Biochemistry, genetics, and biotechnology of glycerol utilization in Pseudomonas species. Microb. Biotechnol. 13 (1), 32-53.

(9) Becker, J., and Wittmann, C. (2019) A field of dreams: Lignin valorization into chemicals, materials, fuels, and health-care products. Biotechnol. Adv. 37 (6), 107360.

(10) Portnoy, V. A., Bezdan, D., and Zengler, K. (2011) Adaptive laboratory evolution-Harnessing the power of biology for metabolic engineering. Curr. Opin. Biotechnol. 22 (4), 590-594.

(11) Dragosits, M., and Mattanovich, D. (2013) Adaptive laboratory evolution-Principles and applications for biotechnology. Microb. Cell Fact. 12, 64.

(12) Winkler, J. D., and Kao, K. C. (2014) Recent advances in the evolutionary engineering of industrial biocatalysts. Genomics 104 (6), 406-411.

(13) Shepelin, D., Hansen, A. S. L., Lennen, R. M., Luo, H., and Herrgård, M. J. (2018) Selecting the best: Evolutionary engineering of chemical production in microbes. Genes 9 (5), 249.

(14) Jang, S., Kim, M., Hwang, J., and Jung, G. Y. (2019) Tools and systems for evolutionary engineering of biomolecules and microorganisms. J. Ind. Microbiol. Biotechnol. 46 (9-10), 1313-1326.

(15) Sandberg, T. E., Salazar, M. J., Weng, L. L., Palsson, B. Ø., and Feist, A. M. (2019) The emergence of adaptive laboratory evolution as an efficient tool for biological discovery and industrial biotechnology. Metab. Eng. 56, 1-16.

(16) Drake, J. W. (1991) A constant rate of spontaneous mutation in DNA-based microbes. Proc. Natl. Acad. Sci. U. S. A. 88 (16), 71607164. 
(17) Lang, G. I., and Murray, A. W. (2008) Estimating the per-basepair mutation rate in the yeast Saccharomyces cerevisiae. Genetics 178 (1), 67-82.

(18) Swings, T., van den Bergh, B., Wuyts, S., Oeyen, E., Voordeckers, K., Verstrepen, K. J., Fauvart, M., Verstraeten, N., and Michiels, J. (2017) Adaptive tuning of mutation rates allows fast response to lethal stress in Escherichia coli. eLife 6, No. e22939.

(19) Kang, M., Kim, K., Choe, D., Cho, S., Kim, S. C., Palsson, B. Ø., and Cho, B. K. (2019) Inactivation of a mismatch-repair system diversifies genotypic landscape of Escherichia coli during adaptive laboratory evolution. Front. Microbiol. 10, 1845.

(20) Wang, X., Li, Q., Sun, C., Cai, Z., Zheng, X., Guo, X., Ni, X., Zhou, W., Guo, Y., Zheng, P., Chen, N., Sun, J., Li, Y., and Ma, Y. (2019) GREACE-assisted adaptive laboratory evolution in endpoint fermentation broth enhances lysine production by Escherichia coli. Microb. Cell Fact. 18 (1), 106.

(21) Foster, P. L. (1991) In vivo mutagenesis. Methods Enzymol. 204, $114-125$.

(22) Kodym, A., and Afza, R. (2003) Physical and chemical mutagenesis. Methods Mol. Biol. 236, 189-204.

(23) Horst, J. P., Wu, T. H., and Marinus, M. G. (1999) Escherichia coli mutator genes. Trends Microbiol. 7 (1), 29-36.

(24) Schaaper, R. M. (1993) Base selection, proofreading, and mismatch repair during DNA replication in Escherichia coli. J. Biol. Chem. 268 (32), 23762-23765.

(25) Aronshtam, A., and Marinus, M. G. (1996) Dominant negative mutator mutations in the mutL gene of Escherichia coli. Nucleic Acids Res. 24 (13), 2498-2504.

(26) Selifonova, O., Valle, F., and Schellenberger, V. (2001) Rapid evolution of novel traits in microorganisms. Appl. Environ. Microbiol. 67 (8), 3645-3649.

(27) Emlyn-Jones, D., Price, G. D., and Andrews, T. J. (2003) Nitrogen-regulated hypermutator strain of Synechococcus sp. for use in in vivo artificial evolution. Appl. Environ. Microbiol. 69 (11), 64276433.

(28) Endo, A., Sasaki, M., Maruyama, A., and Kurusu, Y. (2006) Temperature adaptation of Bacillus subtilis by chromosomal groEL replacement. Biosci., Biotechnol., Biochem. 70 (10), 2357-2362.

(29) Shimoda, C., Itadani, A., Sugino, A., and Furusawa, M. (2006) Isolation of thermotolerant mutants by using proofreading-deficient DNA polymerase delta as an effective mutator in Saccharomyces cerevisiae. Genes Genet. Syst. 81 (6), 391-397.

(30) Luan, G., Cai, Z., Gong, F., Dong, H., Lin, Z., Zhang, Y., and Li, Y. (2013) Developing controllable hypermutable Clostridium cells through manipulating its methyl-directed mismatch repair system. Protein Cell 4 (11), 854-862.

(31) Overbeck, T. J., Welker, D. L., Hughes, J. E., Steele, J. L., and Broadbent, J. R. (2017) Transient MutS-based hypermutation system for adaptive evolution of Lactobacillus casei to low pH. Appl. Environ. Microbiol. 83 (20), No. e01120-17.

(32) Laviña, W. A., Sakurai, S. S. M., Pontrelli, S., Putri, S. P., and Fukusaki, E. (2020) Metabolomics analysis reveals global metabolic changes in the evolved E. coli strain with improved growth and 1butanol production in minimal medium. Metabolites 10 (5), 192.

(33) Kim, S. G., Noh, M. H., Lim, H. G., Jang, S., Jang, S., Koffas, M. A. G., and Jung, G. Y. (2018) Molecular parts and genetic circuits for metabolic engineering of microorganisms. FEMS Microbiol. Lett. 365 (17), fny187.

(34) Nikel, P. I., and de Lorenzo, V. (2018) Pseudomonas putida as a functional chassis for industrial biocatalysis: From native biochemistry to trans-metabolism. Metab. Eng. 50, 142-155.

(35) Poblete-Castro, I., Becker, J., Dohnt, K., Martins dos Santos, V. A. P., and Wittmann, C. (2012) Industrial biotechnology of Pseudomonas putida and related species. Appl. Microbiol. Biotechnol. 93 (6), 2279-2290.

(36) Kivisaar, M. (2020) Narrative of a versatile and adept species Pseudomonas putida. J. Med. Microbiol. 69 (3), 324-338.
(37) Martínez-García, E., and de Lorenzo, V. (2019) Pseudomonas putida in the quest of programmable chemistry. Curr. Opin. Biotechnol. 59, 111-121.

(38) Calero, P., Volke, D. C., Lowe, P. T., Gotfredsen, C. H., O'Hagan, D., and Nikel, P. I. (2020) A fluoride-responsive genetic circuit enables in vivo biofluorination in engineered Pseudomonas putida. Nat. Commun. 11 (1), 5045.

(39) Sánchez-Pascuala, A., Fernández-Cabezón, L., de Lorenzo, V., and Nikel, P. I. (2019) Functional implementation of a linear glycolysis for sugar catabolism in Pseudomonas putida. Metab. Eng. 54, 200-211.

(40) Sánchez-Pascuala, A., de Lorenzo, V., and Nikel, P. I. (2017) Refactoring the Embden-Meyerhof-Parnas pathway as a whole of portable GlucoBricks for implantation of glycolytic modules in Gramnegative bacteria. ACS Synth. Biol. 6 (5), 793-805.

(41) Martínez-García, E., Aparicio, T., de Lorenzo, V., and Nikel, P. I. (2014) New transposon tools tailored for metabolic engineering of Gram-negative microbial cell factories. Front. Bioeng. Biotechnol. 2, 46.

(42) Volke, D. C., Turlin, J., Mol, V., and Nikel, P. I. (2020) Physical decoupling of XylS/Pm regulatory elements and conditional proteolysis enable precise control of gene expression in Pseudomonas putida. Microb. Biotechnol. 13 (1), 222-232.

(43) Wirth, N. T., Kozaeva, E., and Nikel, P. I. (2020) Accelerated genome engineering of Pseudomonas putida by I-SceI-mediated recombination and CRISPR-Cas9 counterselection. Microb. Biotechnol. 13, 233-249.

(44) Durante-Rodríguez, G., de Lorenzo, V., and Nikel, P. I. (2018) A post-translational metabolic switch enables complete decoupling of bacterial growth from biopolymer production in engineered Escherichia coli. ACS Synth. Biol. 7, 2686-2697.

(45) Kuepper, J., Otto, M., Dickler, J., Behnken, S., Magnus, J., Jäger, G., Blank, L. M., and Wierckx, N. (2020) Adaptive laboratory evolution of Pseudomonas putida and Corynebacterium glutamicum to enhance anthranilate tolerance. Microbiology 166 (11), 1025-1037.

(46) Mohamed, E. T., Werner, A. Z., Salvachúa, D., Singer, C. A., Szostkiewicz, K., Jiménez-Díaz, R. M., Eng, T., Radi, M. S., Simmons, B. A., Mukhopadhyay, A., Herrgård, M. J., Singer, S. W., Beckham, G. T., and Feist, A. M. (2020) Adaptive laboratory evolution of Pseudomonas putida KT2440 improves p-coumaric and ferulic acid catabolism and tolerance. Metab. Eng. Commun. 11, No. e00143.

(47) Espeso, D. R., Dvořák, P., Aparicio, T., and de Lorenzo, V. (2020) An automated DIY framework for experimental evolution of Pseudomonas putida. Microb. Biotechnol., in press, DOI: 10.1111/17517915.13678.

(48) Li, W. J., Narancic, T., Kenny, S. T., Niehoff, P. J., O'Connor, K., Blank, L. M., and Wierckx, N. (2020) Unraveling 1,4-butanediol metabolism in Pseudomonas putida KT2440. Front. Microbiol. 11, 382.

(49) Li, W. J., Jayakody, L. N., Franden, M. A., Wehrmann, M., Daun, T., Hauer, B., Blank, L. M., Beckham, G. T., Klebensberger, J., and Wierckx, N. (2019) Laboratory evolution reveals the metabolic and regulatory basis of ethylene glycol metabolism by Pseudomonas putida KT2440. Environ. Microbiol. 21 (10), 3669-3682.

(50) Bator, I., Wittgens, A., Rosenau, F., Tiso, T., and Blank, L. M. (2020) Comparison of three xylose pathways in Pseudomonas putida KT2440 for the synthesis of valuable products. Front. Bioeng. Biotechnol. 7, 480.

(51) Aparicio, T., Nyerges, A., Nagy, I., Pál, C., Martínez-García, E., and de Lorenzo, V. (2020) Mismatch repair hierarchy of Pseudomonas putida revealed by mutagenic ssDNA recombineering of the pyrF gene. Environ. Microbiol. 22 (1), 45-58.

(52) Long, H., Miller, S. F., Williams, E., and Lynch, M. (2018) Specificity of the DNA mismatch repair system (MMR) and mutagenesis bias in bacteria. Mol. Biol. Evol. 35 (10), 2414-2421.

(53) Nyerges, Á., Csörgō, B., Nagy, I., Bálint, B., Bihari, P., Lázár, V., Apjok, G., Umenhoffer, K., Bogos, B., Pósfai, G., and Pál, C. (2016) A highly precise and portable genome engineering method allows comparison of mutational effects across bacterial species. Proc. Natl. Acad. Sci. U. S. A. 113 (9), 2502-2507. 
(54) Aparicio, T., Nyerges, Á., Martínez-García, E., and de Lorenzo, V. (2020) High-efficiency multi-site genomic editing (HEMSE) of Pseudomonas putida through thermoinducible ssDNA recombineering. iScience 23 (3), 100946.

(55) Benedetti, I., Nikel, P. I., and de Lorenzo, V. (2016) Data on the standardization of a cyclohexanone-responsive expression system for Gram-negative bacteria. Data in Brief 6, 738-744.

(56) Akkaya, Ö., Pérez-Pantoja, D., Calles, B., Nikel, P. I., and de Lorenzo, V. (2018) The metabolic redox regime of Pseudomonas putida tunes its evolvability toward novel xenobiotic substrates. mBio 9 (4), No. e01512-18.

(57) Aparicio, T., de Lorenzo, V., and Martínez-García, E. (2019) Improved thermotolerance of genome-reduced Pseudomonas putida EM42 enables effective functioning of the $\mathrm{P}_{\mathrm{L}} / \mathrm{cI} 857$ system. Biotechnol. J. 14 (1), No. 1800483.

(58) Benedetti, I., de Lorenzo, V., and Nikel, P. I. (2016) Genetic programming of catalytic Pseudomonas putida biofilms for boosting biodegradation of haloalkanes. Metab. Eng. 33, 109-118.

(59) Lammens, E. M., Nikel, P. I., and Lavigne, R. (2020) Exploring the synthetic biology potential of bacteriophages for engineering nonmodel bacteria. Nat. Commun. 11, 5294.

(60) Martínez-García, E., Goñi-Moreno, A., Bartley, B., McLaughlin, J., Sánchez-Sampedro, L., Pascual del Pozo, H., Prieto Hernández, C., Marletta, A. S., de Lucrezia, D., Sánchez-Fernández, G., Fraile, S., and de Lorenzo, V. (2020) SEVA 3.0: An update of the Standard European Vector Architecture for enabling portability of genetic constructs among diverse bacterial hosts. Nucleic Acids Res. 48 (D1), D1164-D1170.

(61) Villaverde, A., Benito, A., Viaplana, E., and Cubarsi, R. (1993) Fine regulation of cI857-controlled gene expression in continuous culture of recombinant Escherichia coli by temperature. Appl. Environ. Microbiol. 59 (10), 3485-3487.

(62) Hosokawa, K., Park, N. H., Inaoka, T., Itoh, Y., and Ochi, K. (2002) Streptomycin-resistant ( $r p s L)$ or rifampicin-resistant (rpoB) mutation in Pseudomonas putida KH146-2 confers enhanced tolerance to organic chemicals. Environ. Microbiol. 4 (11), 703-712.

(63) Baltz, R. H. (2014) Spontaneous and induced mutations to rifampicin, streptomycin and spectinomycin resistances in actinomycetes: Mutagenic mechanisms and applications for strain improvement. J. Antibiot. 67 (9), 619-624.

(64) Jatsenko, T., Tover, A., Tegova, R., and Kivisaar, M. (2010) Molecular characterization of $\mathrm{Rif}^{\mathrm{R}}$ mutations in Pseudomonas aeruginosa and Pseudomonas putida. Mutat. Res., Fundam. Mol. Mech. Mutagen. 683 (1-2), 106-114.

(65) Miskinyte, M., and Gordo, I. (2013) Increased survival of antibiotic-resistant Escherichia coli inside macrophages. Antimicrob. Agents Chemother. 57 (1), 189-195.

(66) Ryall, B., Eydallin, G., and Ferenci, T. (2012) Culture history and population heterogeneity as determinants of bacterial adaptation: The adaptomics of a single environmental transition. Microbiol. Mol. Biol. Rev. 76 (3), 597-625.

(67) Galhardo, R. S., Hastings, P. J., and Rosenberg, S. M. (2007) Mutation as a stress response and the regulation of evolvability. Crit. Rev. Biochem. Mol. Biol. 42 (5), 399-435.

(68) Kivisaar, M. (2010) Mechanisms of stationary-phase mutagenesis in bacteria: Mutational processes in pseudomonads. FEMS Microbiol. Lett. 312 (1), 1-14.

(69) Dvořák, P., Chrást, L., Nikel, P. I., Fedr, R., Soucek, K., Sedlacková, M., Chaloupková, R., de Lorenzo, V., Prokop, Z., and Damborský, J. (2015) Exacerbation of substrate toxicity by IPTG in Escherichia coli BL21(DE3) carrying a synthetic metabolic pathway. Microb. Cell Fact. 14, 201.

(70) Silva, F., Queiroz, J. A., and Domingues, F. C. (2012) Evaluating metabolic stress and plasmid stability in plasmid DNA production by Escherichia coli. Biotechnol. Adv. 30 (3), 691-708.

(71) Foster, P. L. (2007) Stress-induced mutagenesis in bacteria. Crit. Rev. Biochem. Mol. Biol. 42 (5), 373-397.

(72) Węgrzyn, G., and Węgrzyn, A. (2002) Stress responses and replication of plasmids in bacterial cells. Microb. Cell Fact. 1 (1), 2.
(73) Juurik, T., Ilves, H., Teras, R., Ilmjärv, T., Tavita, K., Ukkivi, K., Teppo, A., Mikkel, K., and Kivisaar, M. (2012) Mutation frequency and spectrum of mutations vary at different chromosomal positions of Pseudomonas putida. PLoS One 7 (10), No. e48511.

(74) Long, H., Sung, W., Miller, S. F., Ackerman, M. S., Doak, T. G., and Lynch, M. (2015) Mutation rate, spectrum, topology, and context-dependency in the DNA mismatch repair-deficient Pseudomonas fluorescens ATCC948. Genome Biol. Evol. 7 (1), 262-271.

(75) Kivisaar, M. (2020) Mutation and recombination rates vary across bacterial chromosome. Microorganisms 8 (1), 25.

(76) Aparicio, T., Jensen, S. I., Nielsen, A. T., de Lorenzo, V., and Martínez-García, E. (2016) The Ssr protein (T1E_1405) from Pseudomonas putida DOT-T1E enables oligonucleotide-based recombineering in platform strain P. putida EM42. Biotechnol. J. 11, 13091319.

(77) Volke, D. C., Friis, L., Wirth, N. T., Turlin, J., and Nikel, P. I. (2020) Synthetic control of plasmid replication enables target- and self-curing of vectors and expedites genome engineering of Pseudomonas putida. Metab. Eng. Commun. 10, No. e00126.

(78) Watabe, H., Iino, T., Kaneko, T., Shibata, T., and Ando, T. (1983) A new class of site-specific endodeoxyribonucleases. Endo.SceI isolated from a eukaryote, Saccharomyces cerevisiae. J. Biol. Chem. 258 (8), 4663-4665.

(79) Badran, A. H., and Liu, D. R. (2015) Development of potent in vivo mutagenesis plasmids with broad mutational spectra. Nat. Commun. 6 (1), 8425.

(80) Kurusu, Y., Narita, T., Suzuki, M., and Watanabe, T. (2000) Genetic analysis of an incomplete mutS gene from Pseudomonas putida. J. Bacteriol. 182 (18), 5278-5279.

(81) Luján, A. M., Maciá, M. D., Yang, L., Molin, S., Oliver, A., and Smania, A. M. (2011) Evolution and adaptation in Pseudomonas aeruginosa biofilms driven by mismatch repair system-deficient mutators. PLoS One 6 (11), No. e27842.

(82) Colque, C. A., Albarracín Orio, A. G., Feliziani, S., Marvig, R. L., Tobares, A. R., Johansen, H. K., Molin, S., and Smania, A. M. (2020) Hypermutator Pseudomonas aeruginosa exploits multiple genetic pathways to develop multidrug resistance during long-term infections in the airways of cystic fibrosis patients. Antimicrob. Agents Chemother. 64 (5), No. e02142-19.

(83) Luan, G., Bao, G., Lin, Z., Li, Y., Chen, Z., Li, Y., and Cai, Z. (2015) Comparative genome analysis of a thermotolerant Escherichia coli obtained by genome replication engineering assisted continuous evolution (GREACE) and its parent strain provides new understanding of microbial heat tolerance. New Biotechnol. 32 (6), 732738 .

(84) Nikel, P. I., Fuhrer, T., Chavarría, M., Sánchez-Pascuala, A., Sauer, U., and de Lorenzo, V. (2021) Reconfiguration of metabolic fluxes in Pseudomonas putida as a response to sub-lethal oxidative stress. ISME J., in press, DOI: 10.1038/s41396-020-00884-9.

(85) Shibai, A., Takahashi, Y., Ishizawa, Y., Motooka, D., Nakamura, S., Ying, B. W., and Tsuru, S. (2017) Mutation accumulation under UV radiation in Escherichia coli. Sci. Rep. 7 (1), 14531.

(86) Castañeda-García, A., Prieto, A. I., Rodríguez-Beltrán, J., Alonso, N., Cantillon, D., Costas, C., Pérez-Lago, L., Zegeye, E. D., Herranz, M., Plociński, P., Tonjum, T., García de Viedma, D., Paget, M., Waddell, S. J., Rojas, A. M., Doherty, A. J., and Blázquez, J. (2017) A non-canonical mismatch repair pathway in prokaryotes. Nat. Commun. 8, 14246.

(87) Groothuizen, F. S., and Sixma, T. K. (2016) The conserved molecular machinery in DNA mismatch repair enzyme structures. DNA Repair 38, 14-23.

(88) Jacquelín, D. K., Filiberti, A., Argaraña, C. E., and Barra, J. L. (2005) Pseudomonas aeruginosa MutL protein functions in Escherichia coli. Biochem. J. 388 (3), 879-887.

(89) Nyerges, Á., Csorgō, B., Nagy, I., Latinovics, D., Szamecz, B., Pósfai, G., and Pál, C. (2014) Conditional DNA repair mutants enable highly precise genome engineering. Nucleic Acids Res. 42 (8), No. e62. 
(90) Green, M. R., and Sambrook, J. (2012) Molecular cloning: a laboratory manual, 4th ed.; Cold Spring Harbor Laboratory Press: Cold Spring Harbor, NY.

(91) Nour-Eldin, H. H., Geu-Flores, F., and Halkier, B. A. (2010) USER cloning and USER fusion: The ideal cloning techniques for small and big laboratories. Methods Mol. Biol. 643, 185-200.

(92) Choi, K. H., Kumar, A., and Schweizer, H. P. (2006) A 10-min method for preparation of highly electrocompetent Pseudomonas aeruginosa cells: Application for DNA fragment transfer between chromosomes and plasmid transformation. J. Microbiol. Methods 64, 391-397.

(93) Li, H., and Durbin, R. (2009) Fast and accurate short read alignment with Burrows-Wheeler transform. Bioinformatics 25 (14), 1754-1760.

(94) Bonfield, J. K, Marshall, J., Danecek, P., Li, H., Ohan, V., Whitwham, A., Keane, T., and Davies, R. M (2021) Twelve years of SAMtools and BCFtools. GigaScience 10 (2), giab007.

(95) Wang, K., Li, M., and Hakonarson, H. (2010) ANNOVAR: Functional annotation of genetic variants from high-throughput sequencing data. Nucleic Acids Res. 38 (16), No. e164.

(96) Meselson, M., and Yuan, R. (1968) DNA restriction enzyme from E. coli. Nature 217 (5134), 1110-1114.

(97) Bagdasarian, M., Lurz, R., Rückert, B., Franklin, F. C. H., Bagdasarian, M. M., Frey, J., and Timmis, K. N. (1981) Specific purpose plasmid cloning vectors. II. Broad host range, high copy number, RSF1010-derived vectors, and a host-vector system for gene cloning in Pseudomonas. Gene 16 (1-3), 237-247.

(98) Martínez-García, E., Nikel, P. I., Aparicio, T., and de Lorenzo, V. (2014) Pseudomonas 2.0: Genetic upgrading of P. putida KT2440 as an enhanced host for heterologous gene expression. Microb. Cell Fact. 13 (1), 159.

(99) Silva-Rocha, R., Martínez-García, E., Calles, B., Chavarría, M., Arce-Rodríguez, A., de las Heras, A., Páez-Espino, A. D., DuranteRodríguez, G., Kim, J., Nikel, P. I., Platero, R., and de Lorenzo, V. (2013) The Standard European Vector Architecture (SEVA): A coherent platform for the analysis and deployment of complex prokaryotic phenotypes. Nucleic Acids Res. 41 (D1), D666-D675. 